\title{
The Gas7 Gene Encodes Two Protein Isoforms Differentially Expressed within the Brain
}

\author{
Elena M. Lazakovitch, ${ }^{1}$ Bin-Ru She, ${ }^{1}$ Ching-Ling Lien, ${ }^{2}$ Wei-Meng Woo, \\ Yu-Ten Ju, and Sue Lin-Chao ${ }^{3}$ \\ Institute of M olecular Biology, Academia Sinica, Nankang, Taipei, Taiwan 115, Republic of China
}

Received April 19, 1999; accepted August 24, 1999

Gas7, a growth arrest-specific gene first isolated from serum-starved NIH3T3 cells, is expressed abundantly in the brain and is essential for the outgrowth of neurites from cultured cerebellar neurons. Here, we report the existence of a Gas7-related cDNA, designated Gas7-cb, isolated from the mouse cerebellum, and we report the finding that Gas7-cb transcripts and protein are expressed at different locations than those of Gas7. Gas7-cb cDNA differs from the Gas7 cDNA only in the 5' region. Its encoded protein shares the same $\mathbf{3 2 0}$ amino acids in its C-terminus with those of Gas7. Analyses of the RNA and protein expression of Gas7-cb and Gas7 by R Nase protection assay and Western blot indicated that while Gas7 expression is predominant in the cerebrum and in growth-arrested NIH3T3 fibroblasts, Gas7-cb expression is predominant in the cerebellum. Characterization of Gas7 and Gas7-cb RNAs and of the genomic structure of murine Gas7 cloned in a bacterial artificial chromosome indicated that the Gas7 gene spans more than $60 \mathrm{~kb}$ and consists of at least 15 exons. The 5' -terminus of Gas7-cb is located at exon $6 a$, which is absent in Gas7 transcripts but is retained in its entirety in Gas7-cb transcripts, resulting in the presence of a unique 20-aminoacid sequence at the N-terminus of the Gas7-cb protein. Our results show that the Gas7 gene encodes two Gas7 isoforms, Gas7 and Gas7-cb, whose expression is differentially regulated within mouse brain. ๑) 1999 Academic Press

Sequence data from this article have been deposited with the EMBL/GenBank Data Libraries under Accession Nos. (Gas7-cb) AF 133184 and (Gas7 genomic fragment) AF 135442.

${ }^{1}$ Drs. E. M. Lazakovitch and B.-R. She contributed equally toward this work.

${ }^{2}$ Current address: Department of Molecular Biology and Oncology, University of Texas Southwestern Medical Center at Dallas, 6000 Harry Hines Boulevard, Dallas, TX 75235-9148.

${ }^{3}$ To whom correspondence and reprint requests should be addressed. Telephone: 8862 27899218. Fax: 8862 27826085. E-mail: mbsue@ccvax.sinica.edu.tw.

\section{INTRODUCTION}

Growth arrest-specific (Gas) genes are differentially expressed in quiescent cells that enter the G0 state as a result of serum deprivation or growth to confluence (Schneider et al., 1988; Brenner et al., 1989). While preferential expression in G0 is the defining feature of gas genes, they are known to have disparate functions. Gas1 blocks the G0-to-G1 transition of fibroblasts in a p53-dependent manner (Del Sal et al., 1995). Gas2, a microfilament-associated protein cleaved by ICE-like protease upon apoptosis, is involved in cytoskeleton rearrangements during the G0-to-G1 transition (Brancolini and Schneider, 1994) and apoptosis (Brancolini et al., 1995). Gas3 (PMP22), a component of myelin in peripheral nerves, regulates the proliferation and differentiation of Schwann cells (for review, see Naef and Suter, 1998) as well as the proliferation and apoptosis of fibroblasts (Zoidl et al., 1997). Gas6, which is a ligand for receptor tyrosine kinases Axl, Rse, and Mer plays a role in the growth or survival of germ cells, fibroblasts, and Schwann cells (Bellosta et al., 1997; Matsubara et al., 1996; Stitt et al., 1995). Gas9 (Lih et al., 1996) was found to be identical to the plateletderived growth factor $\alpha$ receptor, which has an important role in cellular mitogenic responses and early stage embryogenesis following growth arrest (Pledger et al., 1977; Schatteman et al., 1992).

The Gas7 gene, whose action was first discovered in growth-arrested NIH3T3 fibroblasts using a promotersearch strategy (Brenner et al., 1989), subsequently was found to be expressed prominently in neural tissues and to be implicated in neurite formation during terminal differentiation of cerebellar Purkinje neurons ( $u$ et al., 1998). Whereas antisense inhibition of Gas7 expression impedes neurite outgrowth from maturing Purkinje cells in culture, overexpression of the Gas7 protein promotes neurite outgrowth from undifferentiated Neuro2A neuroblastoma cells ( $u$ et al., 1998). The mouse Gas7 gene maps to chromosome 11 (J u et al., 1998); its human homologue is located in the short arm of chromosome 17 (SHGC-1222, Myers, 1995, Accession No. G13706, unpublished data in Genbank). 
Here we report that the murine Gas7 gene encodes two protein isoforms specified by transcript species that are synthesized differentially within different regions of mouse brains. While expression of Gas7 transcripts and protein is predominant in the cerebrum and in growth-arrested fibroblasts, expression of Gas7-cb transcripts and protein is predominant in the cerebellum. Using genomic sequencing, RNase protection assays, and Western blot analysis, we define the exon organization of the Gas7 gene, the splice junctions of its transcripts, and the tissue-specific expression of Gas7 protein isoforms.

\section{MATERIALS AND METHODS}

Cell culture NIH3T3 cells were cultured in DMEM supplemented with penicillin/streptomycin and $10 \%$ calf serum.

Transfection. Gas7 and Gas7-cb cDNAs were cloned in pcDNA3 (Promega) for transfection. The 5' untranslated region of Gas7-cb CDNA was replaced with the $5^{\prime}$ untranslated region of Gas7 CDNA due to the failure of expression of Gas7-cb protein in NIH3T3 cells with its own natural $5^{\prime}$ untranslated sequence. One microgram of pcDNA3gas7 or pcDNA3gas7-cb cDNA was transfected into each well of NIH3T3 cells (50\% confluence) growing in a 6 -well plate, using Lipofectamine Plus reagent (Gibco BRL). One and a half days after transfection, the cells were collected, and the proteins were extracted with a buffer containing $10 \mathrm{mM}$ Hepes (pH 7.9), $150 \mathrm{mM}$ $\mathrm{NaCl}, 1 \mathrm{mM}$ EDTA, $10 \%$ glycerol, 1\% Nonidet-P 40, and $0.5 \%$ sodium deoxycholate. The protein concentration was measured by a Bio-Rad protein assay.

Western blot. Proteins to be studied were resolved by SDS-PAGE and then transferred to a PVDF membrane with a Bio-Rad semidry transfer cell. The efficiency of transfer was checked by Amido black staining of the membrane. The membrane was blocked with $5 \%$ skim milk in TBST (20 mM Tris, pH 8.0, $150 \mathrm{mM} \mathrm{NaCl}, 0.1 \%$ Tween 20), followed by incubation with rabbit anti-Gas7 serum or anti-Gas7-cb serum diluted 3000-fold with TBST at room temperature for $1 \mathrm{~h}$. After three washes with TBST, the membrane was incubated with sheep anti-rabbit I gG-POD (Boehringer Mannheim) at room temperature for $30 \mathrm{~min}$. This was followed by another three washes with TBST, prior to development with enhanced chemiluminescence reagents (SuperSignal kit, Pierce).

Production of anti-Gas7-cb antibody. A synthetic peptide, consisting of amino acids 1-20 of Gas7-cb (MGKKMSNMENSFDDGSHLSPC-COOH; synthesized by Beckman Center, Stanford University Medical Center), was conjugated to keyhole limpet hemocyanin (KLH) using an Imject activated immunogen conjugation kit (Pierce). The conjugated peptide-KLH was purified by a gel filtration column included in the kit. The immunogen was mixed with Freund's adjuvant (Gibco BRL) and injected subcutaneously into a rabbit. Two hundred micrograms of immunogen was used for the initial injection, and $100 \mu \mathrm{g}$ was used for each subsequent booster injection. The anti-Gas7-cb serum used in this study was obtained after the third booster injection.

RNase protection assay. An RNase protection assay was carried out using an RPAll kit (Ambion). Total RNA was isolated from mouse cerebrum, cerebellum, and contact-inhibited NIH3T3 cells using an RNeasy midi kit (Qiagen). Poly(A) mRNA was purified from total RNA using an Oligotex mRNA mini kit (Qiagen). The purified poly(A) mRNA was subsequently used in these experiments. To make the template for synthesizing the Gas7 probe, a DNA fragment (produced by PCR) covering a region of 44 nucleotides specific to Gas7 and a region of 105 nucleotides shared by Gas7 and Gas7-cb cDNA (see Fig. 1A) was cloned to the EcoRV site of pcDNA3. The template for synthesizing the Gas7-cb probe was similarly made by cloning the DNA fragment containing a region of 46 nucleotides specific to Gas7-cb and a region of 105 nucleotides shared by Gas7 and Gas7-cb cDNA (Fig. 1A) to pcDNA3. Both templates were linearized by $\mathrm{E}$ coRI and transcribed in a mixture (50 $\mu \mathrm{l})$ containing 10 units of Sp6 RNA polymerase (Promega), $1 \mu \mathrm{g}$ of template DNA, 5 mM DTT, 40 units of RNasin (Promega), $1 \times$ TSC buffer (Promega), $0.6 \mathrm{mM}$ ATP/CTP/GTP, $12 \mu \mathrm{M}$ cold UTP, and $50 \mu \mathrm{Ci}$ of $\left[\alpha^{-}{ }^{32} \mathrm{P}\right] \mathrm{UTP}$ $(3000 \mathrm{Ci} / \mathrm{mmol}, \mathrm{NEN})$. The reaction was carried out at $37^{\circ} \mathrm{C}$ for $2 \mathrm{~h}$, followed by destruction of the DNA with 10 units of RNase-free DNase I at $37^{\circ} \mathrm{C}$ for $15 \mathrm{~min}$. The probes were gel-purified. Two micrograms of poly $(\mathrm{A}) \mathrm{mRNA}$ and $1.5 \times 10^{5} \mathrm{cpm}$ probe were used for each RNase protection assay. The protected RNA fragments were analyzed with a $6 \%$ PAGE containing $7 \mathrm{M}$ urea.

Cloning and characterization of Gas7-cb cDNA. The Gas7 and related cDNA, Gas7-cb, were isolated from a newborn mouse brain cDNA library cloned in Lambda ZAP II vector (Stratagene) using Gas7 cDNA as the probe. To isolate the 5' region of Gas7-cb CDNA, a 5' RACE kit purchased from Life Technologies was used. The first-strand CDNA was synthesized by reverse transcription using 20 $\mu \mathrm{g}$ of mouse cerebellum total RNA as the template and a Gas7specific oligonucleotide (5' AGC TTA GCC AGG TTC TTT GC 3') as the primer. A poly $(C)$ tail was added to the $3^{\prime}$ end of the first-strand cDNA by terminal deoxynucleotidyl transferase. The doublestranded CDNA was synthesized by PCR using the first-strand CDNA as the template and using the anchor primer and another Gas7specific oligonucleotide (5' TGC CTT TCA GTT GCT TCT GC 3') as primers. The double-stranded CDNA was then cloned into a PCRII TA cloning vector (I nvitrogen) and sequenced with a T7 Sequenase II reagent kit (USB). The Gas7-cb cDNA was reconstructed by replacing the $5^{\prime}$ region of Gas7 CDNA (Xhol-BamHI fragment) cloned in pSP72NOT (Promega) with the 5' region of Gas7-cb (Xhol-BamHI fragment) cloned in PCRII.

Chromosomal localization of Gas7 by fluorescence in situ hybridization. DNA prepared from the BAC clone was label ed with digoxigenin-dUTP by nick-translation. Labeled probe was combined with sheared mouse DNA and hybridized to normal metaphase chromosomes derived from mouse embryo fibroblast cells in a solution containing $50 \%$ formamide, $10 \%$ dextran sulfate, and $2 \times$ SSC. Specific hybridization signals were detected by incubating the hybridized slides in fluoresceinated antidigoxigenin antibodies followed by counterstaining with DAPI.

Characterization of the Gas7 genomic structure A genomic clone containing the Gas7 gene was isolated from the BAC Mouse ES-129/ Sv) genomic library (Genome Systems Inc.) by screening with a probe corresponding to nucleotides 1-1086 of the Gas7 cDNA. Several approaches were applied to analyze this genomic clone. For identification of the exon/intron boundaries, a sublibrary was first created from this clone. The sublibrary of the BAC clone was prepared by two types of partial restriction-enzyme digestions to ensure adequate cloning coverage: Sau3AI and J on's blunt cocktail (Alul, Hael II, Rsal) (protocol supplied by H.-C. Chi, University of California, I rvine). After gel electrophoresis, restriction fragments (averaging 2.5-3.5 kb in size) were cloned into pBluescript II KS (Stratagene) at the BamHI site for Sau3AI fragments and the EcoRV site for the fragments derived from the digestion with J on's blunt cocktail. In both cases the pBluescript vector was treated with calf intestinal phosphatase. The sublibrary was screened by hybridization using Gas7 cDNA as a probe. The positive clones were subjected to DNA sequence analyses using the T3 and T7 universal primers derived from pBluescript or internal primers derived from the inserts of these clones. Some of the DNA sequences were obtained by direct sequencing of the BAC clone using a cycle sequencing protocol (Amersham Life Science) and Gas7 cDNA-specific primers. The divergence of the cDNA sequences from the genomic sequence was used to identify the exon/intron junctions as shown in Table 1. Next, to characterize introns of less than $5 \mathrm{~kb}$, a pair of primers complementary to the exon margins were used in a PCR amplification with the BAC clone as the template. The PCR products were cloned into pGEM-T vector (Promega), and the end sequences of inserts confirmed the position of these fragments in genomic DNA. Finally, for 
TABLE 1

Gas7 Gene Has Canonical Splice J unctions

\begin{tabular}{|c|c|c|c|c|}
\hline Exon & $\begin{array}{l}\text { Size } \\
\text { (bp) }\end{array}$ & $\begin{array}{l}\text { 3' Splice site } \\
\text { (intron/exon) }\end{array}$ & $\begin{array}{l}\text { 5' Splice site } \\
\text { (exon/intron) }\end{array}$ & $\begin{array}{l}\text { Intron size } \\
\quad(k b)\end{array}$ \\
\hline 4 & 81 & cctttgacag/AGACCACCTG & CCTACAACAG/gtaagagcca & $>13$ \\
\hline 5 & 86 & gtccccacag/TGAATGGATA & TGATTCCCAG/gtaaggggct & $>7$ \\
\hline $6 a b$ & 336 & $5^{\prime}$ UTR & CACCATTACC/gtaagtgggC & 7.5 \\
\hline $6 \mathrm{~b}$ & 54 & ttctccccag/AACCTGGGAT & CACCATTACC/gtaagtgggC & 7.5 \\
\hline 7 & 90 & taccctgcag/ATCAACTGTG & CTACTTTTGG/gtaggtaccg & 2.2 \\
\hline 8 & 116 & ttcttcccag/GCGGACAAGA & TCCGGGAAAG/gtgagctcaa & 3.5 \\
\hline 9 & 75 & ctctttgcag/GATAAAGATT & AGGAGGAAGG/gtgagttggg & $?$ \\
\hline 10 & 79 & cctgttgcag/CTCCTTGGGA & CTCTGCCAAG/gtaaccctcc & 3.5 \\
\hline 11 & 129 & tccttcacag/CTCCACAGCG & AGTGGAGAAG/qtgagaggcc & 1.3 \\
\hline 12 & 124 & cccgctccag/GCCCGCAAAG & ACTCAGGCCG/gtgagcccat & $?$ \\
\hline 13 & 80 & cttttcccag/GAGATGACCT & GACCACACT / gtatgtgatc & 1.4 \\
\hline 14 & 99 & tccttggcag/GAACTGGAGC & CAACCAAAGC/gtgagttccC & 0.8 \\
\hline 15 & 1619 & ccccttgcag/ACAGTCGAGC & 3' UTR & \\
\hline
\end{tabular}

longer introns, the BAC clone was digested with restriction enzymes and probed with the oligonucleotides of the sequences adjacent to the region of interest. When the restriction fragments most likely containing the region of interest were found, they were cloned into pBluescript, mapped, and sequenced.

Southern blot analysis. Four micrograms of genomic DNA isolated from mouse 129/SvJ ES-cells was digested for $6 \mathrm{~h}$ with 35 units of restriction enzymes (as indicated in Fig. 5), separated in a $0.5 \%$ agarose gel, and transferred to Zeta-probe Blotting Mem- brane (Bio-Rad) according to the vendor's instructions. The probes were prepared by random-primed radiolabeling using $\left[\alpha-{ }^{32} \mathrm{P}\right] \mathrm{dCTP}$ as described (Feinberg and Vogelstein, 1983). Templates for making probes 1 and 2 were prepared by PCR amplification. The template for $\mathrm{PCR}$ was the $\mathrm{BAC}$ clone and pairs of primers used for probe 1 and probe 2 were 5' AGT TCC CAC CTC TCT CAT TGT 3', 5' AAG GAA CAG GGA CTC TGA CT 3' and 5' CCT TCT GAA TGA CAC AAC CC 3', 5' ACC TCG GAC TCT GCT GCA CT 3', respectively. The template for third probe contained a $0.75-\mathrm{kb}$

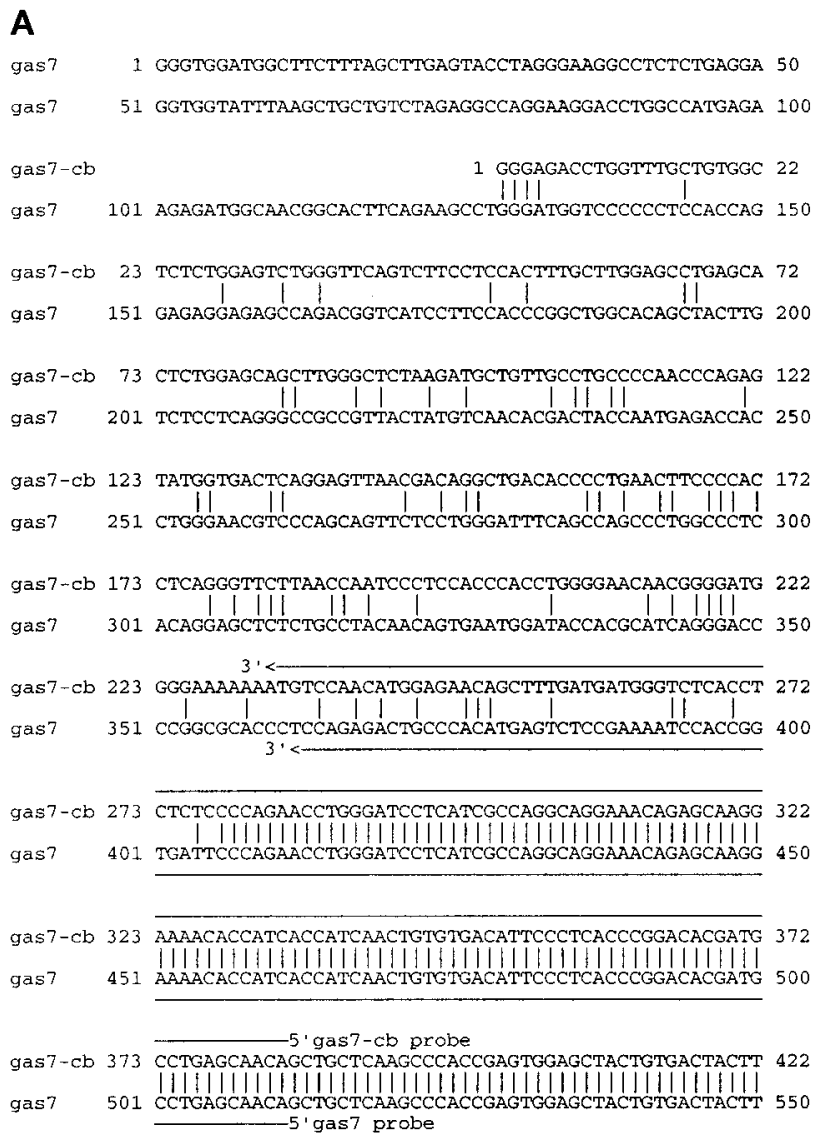

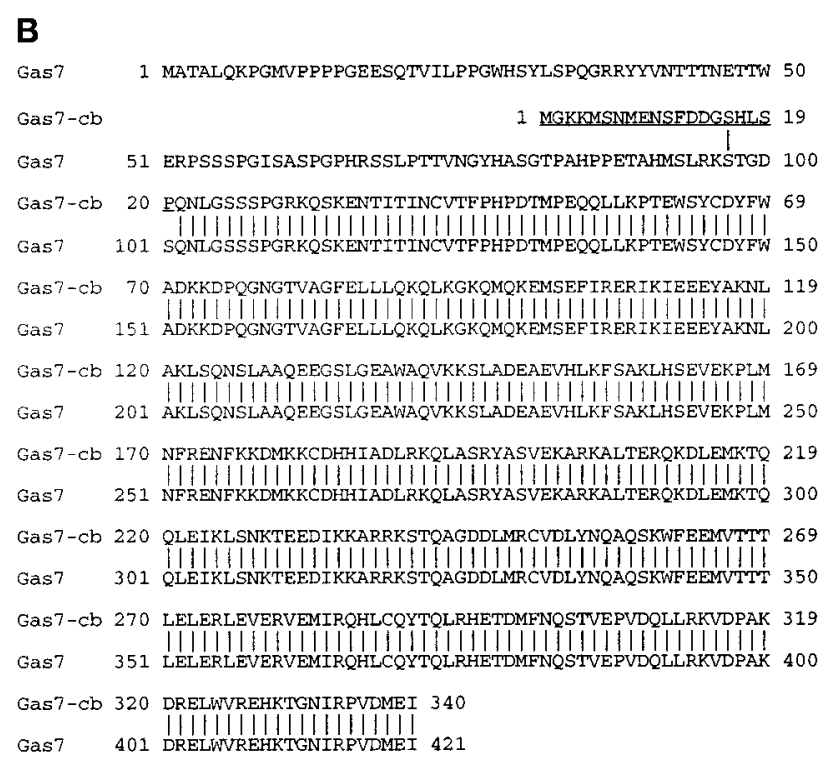

B

FIG. 1. (A) Comparison of the Gas7 and Gas7-cb cDNA. Only the 5' regions of the cDNA are shown. For complete sequences, see Accession Nos. U19860 (Gas7) and AF 133184 (Gas-cb) in GenBank. The antisense Gas7 and Gas7-cb probes used in the RNase protection assay (see Fig. 2) are indicated by arrows. (B) The predicted amino acid sequences encoded by Gas7 and Gas7-cb cDNA. The sequence of the peptide used as the antigen for producing the Gas7-cb antibody (see Fig. 3) is underlined. 


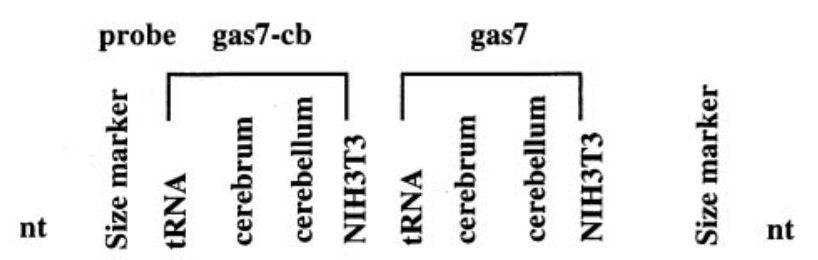

155

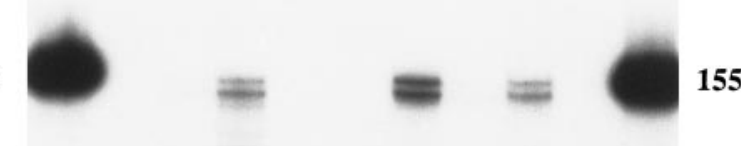

109
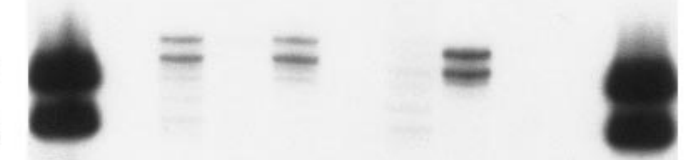

109

103

74

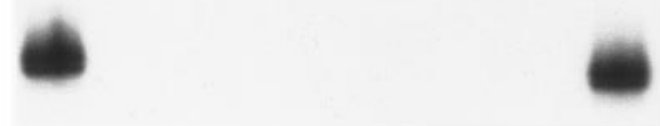

74
1
23
56
$\begin{array}{lll}7 & 8 & 9\end{array}$
10

gas7 RNA
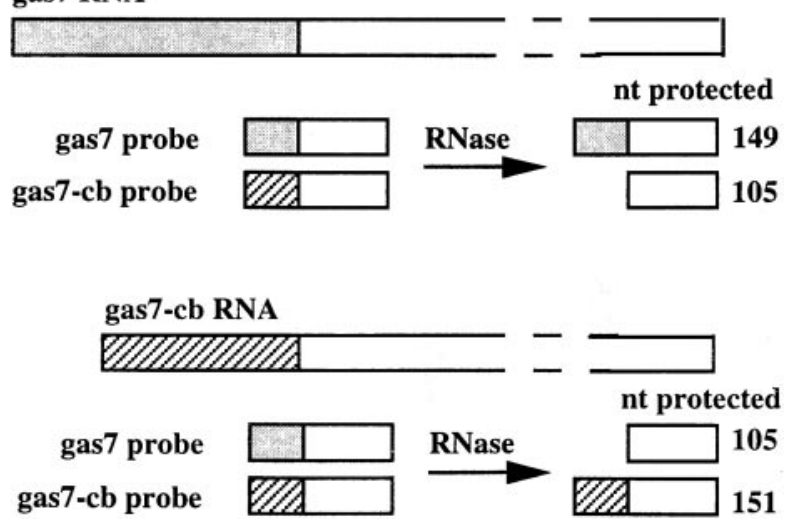

FIG. 2. RNase protection assay with the RNA isolated from the cerebrum, cerebellum, and growth-arrested NIH3T3 cells. Poly(A) mRNA isolated from the tissues or cells indicated was analyzed with the Gas7 and Gas7-cb probes. As shown in the diagrams (bottom), these two probes included a region of 105 nucleotides shared by Gas7 and Gas7-cb (white boxes) and a region specific to Gas7 (shaded boxes) or Gas7-cb (hatched boxes). Hybridization of the Gas7 probeto the Gas7 RNA and Gas7-cb RNA was intended to protect 149- and
Xbal-EcoRI DNA fragment that was derived from a Gas7 genomic fragment isolated from the NIH3T3 cells (| u et al., 1998). Hybridizations were performed using standard protocol (Sambrook et al., 1989).

\section{RESULTS}

\section{A Novel Gas7-Related cDNA Was I solated} from the Brain

Previously, using the Gas7 cDNA as the probe for multitissue Northern bl ot analysis, we detected abundant expression of Gas7 mRNA in mouse brain, where the cerebellum was the area of the brain richest in Gas7 expression (J u et al., 1998). Alternative splicing of Gas7 mRNA was observed in NIH3T3 cells ( ) u et al., 1998), which prompted us to identify other Gas7 mRNA species from the brain tissues by screening of a mouse brain CDNA library and by 5' RACE using RNA extracted from the cerebellum. In addition to Gas7, in the mouse brain cDNA library, we found a Gas7-related CDNA, which was later designated Gas7-cb (Fig. 1). Sequencing of the $5^{\prime}$ RACE products proved the presence of Gas7-cb mRNA in the cerebellum. Comparison of the Gas7 and Gas7-cb cDNAs shows that the nucleotide region 1- 405 of Gas7 is replaced by a different sequence of 277 nucleotides in Gas7-cb (Fig. 1A). As a result, Gas7-cb encodes a 38-kDa protein with its amino acids 21-340 identical to amino acids 102-421 of Gas7 (Fig. 1B).

\section{Gas7 and Gas7-cb mRNAs Are Expressed \\ Differentially in the Brain}

Different protein isoforms can be expressed differentially in different tissues. Since we found both the Gas7 cDNA and the Gas7-cb cDNAs in the brain cDNA library, we further checked their mRNA expression in the cerebrum, cerebellum, and contact-inhibited NIH3T3 cells by RNase protection assay. Two RNA probes, Gas7 and Gas7-cb (Fig. 2), were used to examine the purified poly(A) mRNA, as described under Materials and Methods. The Gas7 RNA probe was designed to yield protected fragments of 149 or 105 nucleotides when hybridized to the Gas7 or Gas7-cb mRNA, respectively. Gas7-cb RNA probe was expected to yield protected fragments of 105 and 151 nucleotides when hybridized to the Gas7 and Gas7-cb mRNA, respectively.

As shown in Fig. 2, the Gas7 probe produced major fragments of about 149 nucleotides when hybridized to the mRNAs isolated from the cerebrum and NIH3T3 cells (Fig. 2, lanes 7 and 9), indicating the predominance of Gas7 mRNA species in these cells. On the other hand, the same probe produced major fragments

105-nucl eotide probe fragments, respectively, from the RN ase digestion while hybridization of the Gas7-cb probe to the Gas7 RNA and Gas7-cb RNA was intended to protect 105- and 151-nucleotide probe fragments, respectively. 
A

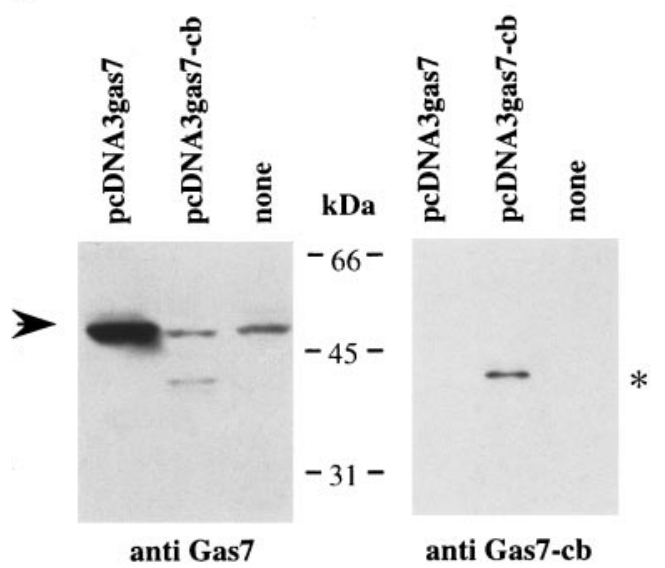

B

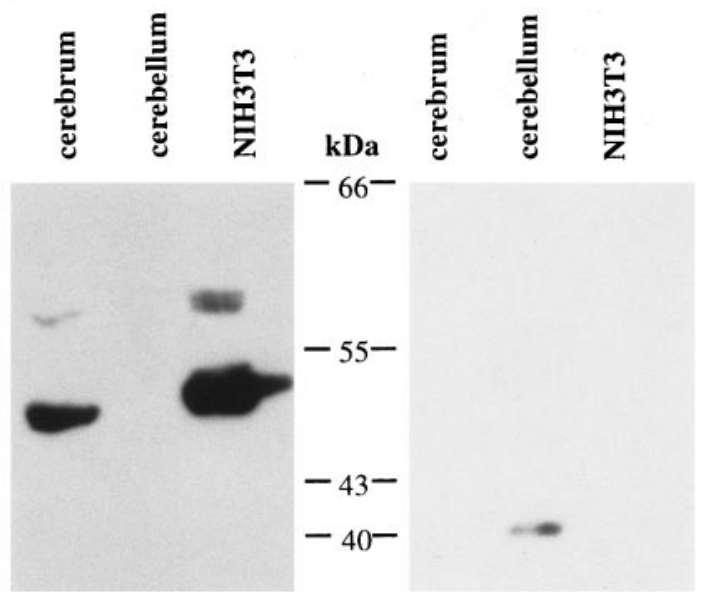

anti Gas7 anti Gas7-cb

FIG. 3. (A) Western bl ot with in vivo synthesized Gas7 and Gas7-cb, using the Gas7 and Gas7-cb antibodies. The Gas7 cDNA and Gas7-cb CDNA cloned in pCDNA3 were transfected into NIH3T3 cells. One and a half days after transfection, $10 \mu \mathrm{g}$ of proteins extracted from transfected and untransfected cells was examined by Western blot. The membrane was first probed with the Gas7-cb antibody (also described in Fig. 1B), which detected an approximately 40-kDa band (indicated by an asterisk, right) only in the sample transfected with pcDNA3gas7$\mathrm{cb}$. The membrane was stripped of the probe and then probed again with the Gas7 antibody, which detected both the endogenous Gas7 and the transfected Gas7 (indicated by an arrow, left). The Gas7 antibody detected the transfected Gas7-cb as well, but to a much lesser extent. (B) Western blot with the extracts from the cerebrum, cerebellum, and growth-arrested NIH3T3 cells. $15 \mu \mathrm{g}$ of proteins from each of the tissues and the contact-inhibited NIH3T3 cells was probed by the Gas7 and Gas7-cb antibodies. The Gas7-cb antibody detected a band of about $40 \mathrm{kDa}$ in the cerebellum sample (right) while the Gas7 antibody detected bands of approximately $48 \mathrm{kDa}$ in the cerebrum and NIH 3T3 samples (left).

of about 105 nucleotides when the cerebellum mRNA was examined (Fig. 2, lane 8), indicating the predominance of Gas7-cb in the cerebellum. The fragments of the Gas7-cb probe protected by the cerebrum and NIH3T3 mRNA were nearly 105 nucleotides in length (Fig. 2, lanes 3 and 5 ) while those protected by the cerebellum mRNA were nearly 151 nucleotides in length (Fig. 2, lane 4). These results agree with the conclusion that the Gas7 mRNA species is predominant in the cerebrum and contact-inhibited NIH3T3 cells while the Gas7-cb mRNA species is predominant in the cerebellum. The negative control of tRNA gave no protection to either probe (Fig. 2, lanes 2 and 6).

\section{Western Blot Confirmed the Differential Expression of Gas7 and Gas7-cb}

The differential expression of Gas7 and Gas7-cb was checked at the protein level by Western blot. The specificity of the Gas7-cb antibody was tested with the in vivo synthesized proteins (Fig. $3 A$ ) as described under Materials and Methods. The Gas7-cb antibody detected only the Gas7-cb protein but not the other proteins ( $\mathrm{F} \mathrm{ig}$ $3 \mathrm{~A}$, right), proving the specificity of the antibody. Another antibody, Gas7, which was produced using fulllength Gas7 as the antigen ( $\mathrm{u}$ et al., 1998), reacted strongly to endogenous NIH3T3 Gas7 and transfected Gas7 but reacted poorly to Gas7-cb (Fig 3A, left). Gas7 and Gas7-cb share a common region of 320 amino acids but differ in their $\mathrm{N}$-terminal regions. It is possible that the Gas7 antibody reacts mainly to the $\mathrm{N}$-terminal region of Gas7. Using Gas7 and Gas7-cb antibodies, the tissue-specific expression of Gas7 and Gas7-cb was examined by Western blot analysis (Fig. 3B). The Gas7-cb antibody revealed a band in the cerebellum sample of about $40 \mathrm{kDa}$, close to the predicted size of the protein encoded by the Gas7-cb CDNA (Fig. 3B, right). The Gas7 antibody revealed a major band of approximately $48 \mathrm{kDa}$ in the cerebrum and NIH3T3 samples. The 40-kDa band in the cerebellum sample was also detected by the Gas7 antibody when the film was exposed for a longer period (data not shown), suggesting its relevance to Gas7. These results confirm the RNA analysis data showing that Gas7-cb is predominant in the cer ebellum and Gas7 is predominant in the cerebrum and NIH3T3 cells.

\section{The Gas7 Gene Encodes Both Gas7 and Gas7-cb cDNA}

The BAC clone isolated from the BAC M ouse ES-129/ SvJ genomic library (Genome Systems Inc.) using the Gas7 CDNA probe contained an insert longer than 100 $\mathrm{kb}$. From the DNA sequence analysis and PCR analysis described under Materials and Methods, we mapped regions that encode Gas7 and Gas7-cb.

Comparison of CDNA and genomic DNA sequences reveal ed the exon organization of the Gas7 gene (Fig. 4). The splicing site sequences (Table 1 ) agree with the known consensus sequence (Breathnach and Chambon, 1981). The Gas7 gene in the BAC clone contains 12 exons and spans more than $60 \mathrm{~kb}$. The present 12 exons, which encode nucleotides 244-2875 of the Gas7 cDNA, represent $91.5 \%$ of the full-length Gas7 CDNA. 


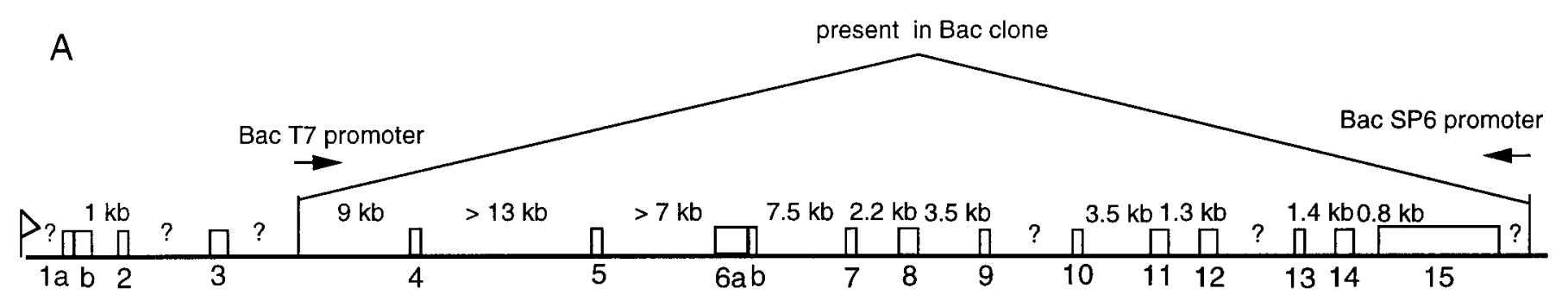

$\mathrm{B}$

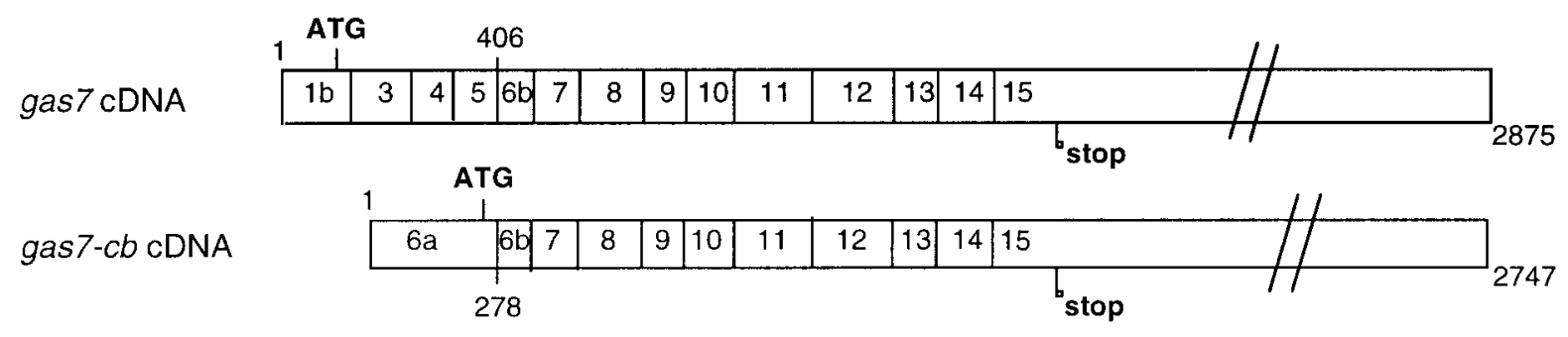

C

cttgctgacg atggggacag tatataaaag gcacccagaa ggatgctgtg catatgggaa gtcactgtgg cttccaggta cactgccaag gtggctgggc agagcccatg ttcgttcacc gtctgacatt atggactcgg ggggatgggg gcacgttcag aatgagatgt cacgtgctga gtcctctgtg cctgggggag ggcggggaag gtggcctaca atctgcctta actctctgct cccctgtcat tccactccca tgcttccgca acgtggtctg gttaccagca gagggcagtg gaggggttaa ctctccaaat cccagttgga aaggagagga aGGGAGACCT GGTTTGCTGT GGCTCTCTGG AGTCTGGGTT CAGCCTTCCT CCACTTTGCT TGGAGCCTGA GCACTCTGGA GCAGCTTGGG CTCTAAGATG CTGCTGCCTG CCCCAACCCA GAATATGGTG ACTCAGGAGT TAACGACAGG CTGACACCCC TGAACTTCCC CACCTCAGGG TTCTTAACCA ATCCCTCCAC CCACCTGGGG AACAACGGGG ATGGGGAAAA AAATGTCCAA CATGGAGAAC AGCTTTGATG ATGGGTCTCA CCTTTCTCCC CAG AACCTGG GATCCTCATC GCCAGGCAGG AAACAGAGCA AGGAAACAC CATTACC gta agtgggetca ctgtgggcgg ggagggctcc agggctgggg ctttgggcca cagctggggt tgttgccatg gcaacgtgga tcgccaacca gaatcgatgc tcactgggaa acagagaagt tgcagccaaa tcttggattt tagctgaagt tgcccccatt ccctccctct gtcagtttcc catttcactt gcactcttct ggtgaagggg tggaggaggg cagaaggctg taaccaggga gaagctgttt ctgtgtggtg ggcaggagaa ggtgcttgtg ggggagcgag ttgaaggggg tggagtgtgc tgtgtgca

FIG. 4. (A) Genomic structure of the Gas7 gene. Exons are depicted as rectangles; sizes of introns are indicated above the solid line. The sizes of exons and introns are not drawn to scale. The part of the Gas7 gene present in the BAC clone and the orientation of the gene relative to the T7 and Sp6 promoters in the vector are shown. (B) Exon organization of Gas7 and Gas7-cb cDNA. The sequence analyses of Gas7 genomic DNA, Gas7 cDNA, and Gas7-cb cDNA showed that exons 6a and 6b form the first exon of Gas7-cb while in Gas7 exon 5 joins exon 6b. The locations of the translation initiation and stop codons are shown. (C) The sequence of the genomic DNA fragment (GenBank Accession No. AF 135442) that contains exon 6ab. These data were obtained from direct sequencing of the BAC clone and the insert of J 1-24, a clone of the library containing the fragments of the restriction enzyme (Alul, HaelI, Rsal) digested BAC clone. Lowercase letters indicate intron sequences, and uppercase letters denote exon $6 a b$, where exon $6 \mathrm{~b}$ is shown in boldface type.

The $5^{\prime}$ region of the Gas7 gene is missing from this genomic clone. We had previously sequenced a part of the 5' region of the Gas7 gene located upstream of an Escherichia coli lacZ gene inserted into the NIH3T3 chromosome as a result of our promoter search ( $\mathrm{u}$ et al., 1998). The sequenced region contains 2 additional exons. F urthermore, a sequence present in Gas7 cDNA is still missing from this region and the BAC clone. These data indicate that the region of the Gas7 gene absent from the BAC clone consists of at least three exons (as shown in Fig. 4). Nucleotides 1-336 of Gas7-cb cDNA correspond to the entire exon 6, i.e., 6a and $6 \mathrm{~b}$, of the Gas7 genomic DNA (Fig. 4C). However, in Gas7 cDNA, exon 5 is spliced directly to exon $6 b$, and as a result, exon $6 a$ is absent.

To reveal the localization of the Gas7 locus in mouse chromosomes, using a Gas7 probe derived from the BAC clone, we performed fluorescence in situ hybridization (FISH) on normal metaphase chromosomes derived from mouse embryo fibroblast cells. The initial experiment resulted in specific labeling of a mediumsized chromosome that was believed to be chromosome 11 (data not shown), which is consistent with a previous report ( $u$ et al., 1998). Subsequently, a probe specific for the centromeric region of chromosome 11 was cohybridized with the Gas7 probe, confirming that Gas7 is located as single locus on chromosome 11 (Fig. 5). Furthermore, the Gas7 gene was found to hybridize specifically at a position that is $50 \%$ of the distance from the heterochromatic-euchromatic boundary to the terminus of chromosome 11 (Fig. 5; a total of 80 metaphase cells were analyzed with 72 exhibiting spe- 


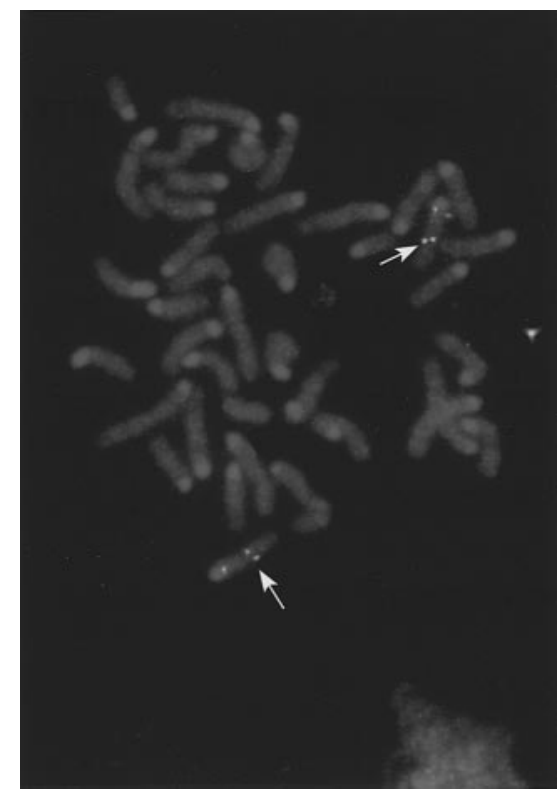

FIG. 5. Chromosomal localization of the Gas7 gene. The BAC clone containing Gas7 genomic DNA was labeled with digoxigenindUTP by nick-translation, mixed with sheared mouse DNA, and hybridized to normal metaphase chromosomes derived from mouse embryo fibroblasts, as described (Stokke et al., 1995). Specific hybridization signals were detected using fluoresceinated antidigoxigenin antibodies followed by counterstaining with DAPI. A total of 80 metaphase cells were analyzed with 72 cells exhibiting specific labeling (indicated with arrows). A hybridization signal labeled by a probe specific for the centromeric region of chromosome 11 (Shi et al., 1997) is also revealed.

cific labeling). Although FISH reveals the locus of a gene, Southern analysis provides better resolution in determining gene copy number and in detecting the presence of related genes (for related information see Davies and Tilghman, 1990). We performed Southern blot analysis on the genomic DNA purified from mouse strain $129 / \mathrm{Sv}$. Three DNA probes derived from various regions of the Gas7 genomic DNA were used in these experiments (see Materials and Methods). As shown in Fig. 6, in each Southern bl ot analysis only one single band was detected for each restriction enzyme cleaved genomic DNA. These results indicate that Gas7 is very likely a single-copy gene, which agrees with the results mentioned above that the same gene encodes Gas7 and Gas7-cb.

\section{DISCUSSION}

Genes encoding a diverse array of protein isoforms via tissue-specific transcription and developmentally regulated alternative mRNA splicing are widespread in mammals (Suter et al., 1994; K hvotchev and Sudhof, 1998; Ashiya and Grabowski, 1997). Analysis of Gas7 genomic structure and of Gas7 and Gas7-cb mRNA indicates that the same locus encodes both Gas7 and Gas7-cb. The 5' end of mouse Gas7-cb is present in the genomic sequence (entire exon 6), while the $5^{\prime}$ end (exon 1) of mouse Gas7 is located far upstream. The nearest TATA box (TATAAAA) is $270 \mathrm{bp}$ upstream of the first nucleotide of Gas7-cb. No consensus splice acceptor sequence (AG) is adjacent to the first nucleotide of Gas7-cb. Our findings suggest that mouse Gas7-cb and Gas7 may be transcribed from different promoters, but the possibility that Gas7 and Gas7-cb mRNA species result from alternative splicing is not excluded. Interestingly, gene regulation by the use of different promoters has been reported for Gas3 (PMP22), in which one promoter is used in neuronal cells while the other is used in nonneuronal cells, resulting in the production of tissue-specific transcripts (Desarnaud et al., 1998; Suter et al., 1994).

A human cDNA homologue of Gas7 isolated by Ohara et al. (1999, unpublished sequence in Genbank, Accession No. AB007854), shows $72.9 \%$ similarity to mouse Gas7 cDNA, and the predicted protein sequences have $98.3 \%$ similarity. During the present

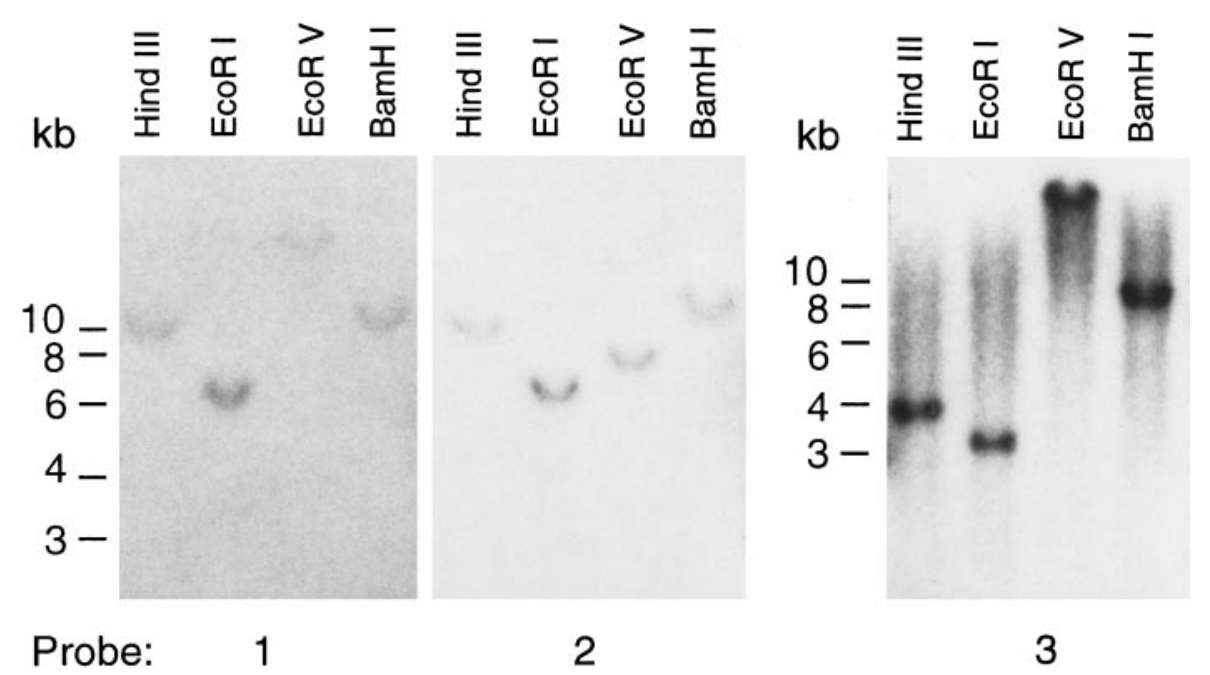

FIG. 6. Southern blot with genomic DNA from mouse 129/SvJ ES cells. Genomic DNA, digested with the restriction enzymes indicated, was probed with three DNA fragments (shown as probes 1,2 , and 3). Probes 1 (0.8 kb) and 2 (1 kb) are located 1.65 and $0.4 \mathrm{~kb}$ upstream of exon 4, respectively. Probe $3(0.75 \mathrm{~kb})$ covering part of exon 1 and the intron downstream was derived from a Gas7 genomic DNA fragment isolated from NIH3T3 cells (J u et al., 1998). Size markers are indicated on the left side of the autoradiographs. 
study, we obtained a human homologue of Gas7-cb from the cerebellum (Chao, 1999, unpublished sequence in Genbank, Accession No. AJ 224876), suggesting that both of the Gas7 protein isoforms we identified in murine tissues are also made in human tissues. Mouse Gas7-cb has 74.9 and $98.8 \%$ similarity to its human homologue at the nucleotide and predicted protein sequence levels, respectively. Comparison of the human GAS7 genomic sequence (Birren et al., 1998, unpublished sequence in Genbank, Accession No. AC005747) with human GAS7 and GAS7-cb CDNA shows that the exon/intron organization of Gas7 is conserved between human and mouse.

Previously, using anti-Gas7 antibodies, we detected strong immunohistochemistry reactivity in the cer ebellum ( $u$ et al., 1998). In the present study, it is shown that this anti-Gas7 antibody reacts less strongly to cerebellum Gas7-cb analyzed by Western blot. It is possible that while the anti-Gas7 antibodies strongly react to the N-terminal region of denatured Gas7 (as in the case of Western analysis), they recognize the Cterminal region of a folded native Gas7 or Gas7-cb protein (as in the case of immunohistochemistry analysis). Prolonged exposure of films for RNase protection and use of large amounts of extracts in Western blot analysis showed that Gas7 mRNA and protein are present in small amounts in the cerebellum and that Gas7-cb mRNA and protein are also present in limited amounts in the cerebrum (data not shown). Thus, while expression of Gas7 is predominant in the cerebrum and that of Gas7-cb is predominant in the cerbellum, the specificity of expression is not absolute.

The Gas7 gene is a novel gene originally isolated from growth-arrested NIH 3 T 3 cells. I ts overexpression in Neuro2A neuroblastoma cells resulted in the production of extensive cellular processes (J u et al., 1998), suggesting that Gas7 may participate in the cytoskeleton reorganization during the formation of cellular processes. When cultured cerebellar neurons were treated with antisense oligonudeotides complementary to sequences in the translation initiation regions of Gas7 and Gas7-cb, neurite outgrowth was inhibited ( $\mathrm{u}$ et al., 1998). As the oligonucleotides employed in those experiments knocked out both proteins encoded by Gas7 and Gas7-cb, whether the observed inhibition of neurite outgrowth resulted from interference with expression of Gas7, Gas7-cb, or both remains to be revealed. The N-terminal region of Gas7, absent in Gas7-cb, contains a sequence (amino acids 2-30) similar to a region in transcription factor Oct-2 (Wirth et al., 1991) and a region in synapsins I a/b (Südhof et al., 1989, Accession Nos. M27924 and M27812), which tether synaptic vesicles to cytoskel etons (Sudhof, 1995) and induce the formation of elongated processes when overexpressed in neuronal (Han et al., 1991) or fibroblast (Han and Greengard, 1994) cells. The N-terminal region also contains a WW motif (amino acids 22-60) whose prominent feature is the presence of two conserved tryptophans (W) (Sudol, 1996). However, both
Gas7 and Gas7-cb were able to promote the formation of long processes when overexpressed in NIH3T3 cells (unpublished data). The WW motif is widely involved in protein interactions (Sudol, 1996). If this motif plays a role in Gas7 function by mediating the interaction between Gas7 and other proteins, Gas7 and Gas7-cb may have different biological functions.

\section{ACKNO WLEDGMENTS}

We thank Dr. Hang-Chang Chi for providing helpful information for analyzing the BAC clone, Dr. Chuck C.-K. Chao for comparison of human genomic sequence with the human Gas7 cDNA, and Drs. Stanley N. Cohen, Michael O. Poulter, Dmitri A. Bessarab, and Chih-J ian Lih for hel pful discussions. Wealso thank Ying-J iun Chen and Cheng-Hang Liu for plasmid constructions. This study was supported by a Frontier Research Award from the National Science Council of Taiwan, Republic of China, to S. Lin-Chao (NSC 87-2312B-001-017). E.M.L. was supported by the Academia Sinica, Taiwan; B.-R.S. received a postdoctoral fellowship from the National Science Council, the Republic of China.

\section{REFERENCES}

Ashiya, M., and Grabowski, P. J . (1997). A neuron-specific splicing switch mediated by an array of pre-mRNA repressor sites: Evidence of a regulatory role for the polypyrimidine tract binding protein and brain-specific PTB counterpart. RNA 3: 996-1015.

Bellosta, P., Zhang, Q., Goff, S. P., and Basilico, C. (1997). Signaling through the ARK tyrosine kinase receptor protects from apoptosis in the absence of growth stimulation. Oncogene 15: 2387-2397.

Brancolini, C., and Schneider, C. (1994). Phosphorylation of the growth arrest-specific protein Gas2 is coupled to actin rearrangements during G0 > G1 transition in NIH3T3 cells. J. Cell. Biol. 124: 743-756.

Brancolini, C., Benedetti, M., and Schneider, C. (1995). Microfilament reorganization during apoptosis: The role of Gas2, a possible substrate for ICE-like proteases. EMBO J . 14: 5179-5190.

Breathnach, R., and Chambon, P. (1981). Organization and expression of eucaryotic split genes coding for proteins. Annu. Rev. Biochem. 50: 349-383.

Brenner, D. G., Lin-Chao, S., and Cohen, S. N. (1989). Analysis of mammalian cell genetic regulation in situ by using retrovirusderived "portable exons" carrying the Escherichia coli lacZ gene. Proc. Natl. Acad. Sci. USA 86: 5517-5521.

Chi, H.-C., Saunders, E. H., Buckingham, J . M., Ricke, D. O., Munk, A. C., Lobb, R., Ueng, S. Y.-J ., Shi, Y., Mundt, M. O., White, P. S., Tatum, O. L., Riethman, H. C., and Moyzis, R. K. DNA sequence analysis of the terminal $226 \mathrm{~kb}$ of human chromosome 7q. Submitted for publication.

Davies and Tilghman (Eds.) (1990). A fluorescence in situ hybridization approach for gene mapping and the study of nuclear organization. In "Genetic and Physical Mapping," pp. 1-38, Cold Spring Harbor Laboratory Press, Cold Spring Harbor, NY.

Del Sal, G., Ruaro, E. M., Utrera, R., Cole, C. N., Levine, A. J ., and Schneider, C. (1995). Gasl-induced growth suppression requires a transactivation-independent p53 function. Mol. Cell. Biol. 15: 7152-7160.

Desarnaud, F., Do Thi, A. N., Brown, A. M., Lemke, G., Suter, U., Baulieu, E.-E., and Schumacher, M. (1998). Progesterone stimulates the activity of the promoters of peripheral myelin protein-22 and protein zero genes in Schwann cells. J . Neurochem. 71: 17651768.

Feinberg, A. P., and Vogelstein, B. (1983). A technique for radiolabeling DNA restriction endonuclease fragments to high specific activity. Anal. Biochem. 132: 6-13. 
Han, H.-Q., Nichols, R. A., Rubin, M. R., Bahler, M., and Greengard, P. (1991) Nature 349: 697-700.

Han, H.-Q, and Greengard, P. (1994). Remodeling of cytoskeletal architecture of nonneuronal cells induced by synapsin. Proc. Natl. Acad. Sci. USA 91: 8557-8561.

J u, Y.-T., Chang, A. C. Y., She, B.-R., Tsaur, M.-L., Hwang, H.-M., Chao, C. C.-K., Cohen, S. N., and Lin-Chao, S. (1998). gas7: A gene expressed preferentially in growth-arrested fibroblasts and terminally differentiated Purkinje neurons affects neurite formation. Proc. Natl. Acad. Sci. USA 95: 11423-11428.

Khvotchev, M., and Sudhof, T. C. (1998). Developmentally regulated alternative splicing in a novel synaptojanin. J . Biol. Chem. 273: 2306-2311.

Lih, C.-J ., Cohen, S. N., Wang, C., and Lin-Chao, S. (1996). The platelet-derived growth factor $\alpha$-receptor is encoded by a growtharrest-specific (gas) gene. Proc. Acad. Sci. USA 93: 4617- 4622.

Matsubara, N., Takahashi, Y., Nishina, Y., Mukouyama, Y., Yanagisawa, M., Watanabe, T., Nakano, T., Nomura, K., Arita, H., Nishimune, Y., Obinata, M., and Matsui, Y. (1996). A receptor tyrosine kinase, Sky, and its ligand Gas6 are expressed in gonads and support primordial germ cell growth or survival in culture. Dev. Biol. 180: 499-510.

Naef, R., and Suter, U. (1998). Many facets of the peripheral myelin protein PMP22 in myelination and disease. Microsco. Res. Tech. 41: 359-371.

Pledger, W. J., Stiles, C. D., Antoniades, H. N., and Scher, C. D. (1977). Induction of DNA synthesis in BALB/c 3T3 cells by serum components: Reevaluation of the commitment process. Proc. Natl. Acad. Sci. USA 74: 4481- 4485.

Sambrook, J., Fritsch, E. F., and Maniatis, T. (1989). "Molecular Cloning: A Laboratory Manual," 2nd ed., Cold Spring Harbor Laboratory Press, Cold Spring Harbor, NY.

Schatteman, G. C., Morrison-Graham, K., van Koppen, A., Weston, J . A., and Bowen-Pope, D. (1992). Regulation and role of PDGF receptor alpha-subunit expression during embryogenesis. Devel opment 115: 123-131.

Schneider, C., King, R. M., and Philipson, L. (1988). Genes specifically expressed at growth arrest of mammalian cells. Cell 54: 787-793.
Shi, Y.-P., Mohapatra, G., Miller, J ., Hanahan, D., Lander, E., Gold, P., Pinkee, D., and Gray, J . (1997). FISH probes for mouse chromosome identification. Genomics 45: 42- 47.

Stitt, T. N., Conn, G., Gore, M., Lai, C., Bruno, J ., Radziejewski, C., Mattsson, K., Fisher, J ., Gies, D. R., J ones, P. F., Masiakowski, P., Ryan, T. E., Tobkes, N. J ., Chen, D. H., DiStefano, P. S., Long, G. L., Basilico, C., Goldfarb, M. P., Lemke, G., Glass, D. J ., and Yancopoulos, G. D. (1995). The anticoagulation factor protein S and its relative, Gas6, are ligands for the Tyro 3/Axl family of receptor tyrosine kinases. Cell 80: 661-670.

Stokke, T., Collins, C., Kuo, W.-L., Kowbel, D., Shadravan, F., Tanner, M., Kallioniemi, A., Kallioniemi, O.-P., Pinkel, D., Deaven, L., and Gray, J. W. (1995). A physical map of chromosome 20 established using fluorescence in situ hybridization (FISH) and digital image analysis. Genomics 26: 134-137.

Südhof, T. C. (1995). The synaptic vesicle cycle: A cascade of proteinprotein interactions. Nature 375: 645- 653.

Südhof, T. C., Czernik, A. J ., Kao, H. T., Takei, K., J ohnston, P. A., Horiuchi, A., Kanazir, S. D., Wagner, M. A., Perih, M. S., De Camilli, P., and Greengard, P. (1989). Synapsins: Mosaics of shared and individual domains in a family of synaptic vesicle phosphosproteins. Science 245: 1474-1480.

Sudol, M. (1996). The WW module competes with the SH3 domain? Trends Biochem. Sci. 21: 161-163.

Sudol, M., Chen, H. I., Bougeret, C., Einbond, A., and Bork, P. (1995). Characterization of a novel protein-binding module-The WW domain. FEBS Lett. 369: 67-71.

Suter, U., Snipes, G. J ., Schoener-Scott, R., Welcher, A. A., Pareek, S., Lupski, J. R., Murphy, R. A., Shooter, E. M., and Patel, P. I. (1994). Regulation of tissue-specific expression of alternative peripheral myelin protein-22 (PM22) gene transcripts by two promoters. J . Biol. Chem. 269: 25795-25808.

Wirth, T., Priess, A., Annweiler, A., Zwilling, S., and Oeler, B. (1991). Multiple Oct2 isoforms are generated by alternative splicing. Nucleic Acids Res. 19: 43-51.

Zoidl, G., D'Urso, D., Blass-Kampmann, S., Schmalenbach, C., Kuhn, R., and Muller, H. W. (1997). I nfluence of el evated expression of rat wild-type PMP22 and its mutant PMP22 $2^{\text {Trembler }}$ on cell growth of NIH3T3 fibroblasts. Cell Tissue Res. 287: 459- 470. 